\title{
Impact of digital transformation on the individual job performance of insurance companies in Peru
}

\author{
Carla Victoria Guzmán-Ortiz ${ }^{a}$, Nohelia Gabriela Navarro-Acosta ${ }^{a}$, Wilmer Florez-Garcia ${ }^{a}$ and \\ Wagner Vicente-Ramos ${ }^{{ }^{*}}$
}

\section{${ }^{a}$ Universidad Continental, Peru \\ C H R O N I C L E}

\section{Article history:}

Received: July 20, 2020

Received in revised format: $\mathrm{Au}-$ gust 29, 2020

Accepted: September 21, 2020

Available online: September 21, 2020

Keywords:

Digital transformation

Individual job performance

Customer service experience

Employee capabilities

Business model

\begin{abstract}
A B S T R A C T
The objective of this study was to analyze and determine the impact of digital transformation on the individual job performance of insurance companies in Peru. The deductive inferential scientific method of explanatory level was used, with a non-experimental design, to four insurance companies that operate in the regions of Arequipa, Cusco, Iquitos, Lima, Tacna and Trujillo. The results generated by structural equations show that customer service experience (CSE), based on digital transformation, had a positive impact on task performance $(p<0.05)$ and contextual performance $(\mathrm{p}<0.05)$; in contrast, the customer service experience (CSE), based on digital transformation, was found to have no impact on counterproductive behavior ( $p>0.05)$. In relation to the collaborator's capabilities (CC) based on digital transformation, the results reveal that it had a significant influence on task performance $(\mathrm{p}<0.05)$ and contextual performance $(\mathrm{p}<0.05)$, while it did not have any impact on counterproductive behavior $(p>0.05)$. Likewise, processes based on digital transformation $(\mathrm{P})$ significantly influence task performance $(\mathrm{p}<0.05)$ and contextual performance $(p<0.05)$, unlike counterproductive behavior that did not present a causal link with the processes $(p>0.05)$. Finally, the business model based on digital transformation (BM) had no implications for task performance $(p>0.05)$, contextual performance $(p>0.05)$ and counterproductive behaviors ( $p>0.05$ ). The conclusion of the study indicates that the customer service experience, the collaborator's capabilities and processes based on digital transformation contribute to the performance and contextual performance of the workers of the insurance companies in Peru.
\end{abstract}

(C) 2020 by the authors; licensee Growing Science, Canada.

\section{Introduction}

Currently, we are living a fairly advanced phase of the digital age, so that constant innovations in communication technologies have changed the way in which organizations communicate with their customers, thus replacing traditional business models, in which obtaining data required investment in sophisticated computer systems and innovation studies had a very high cost, due to this, most decisions were based on the analysis and intuition of managers (Rogers, 2016). Today, there are cloud-based systems that are increasingly cheap and easy to use, these new technologies are based on analytical applications, artificial intelligence, big data, internet of things, robotics, among others (Stark, 2020). However, technology alone does nothing, it requires knowing the environment surrounding digital transformation. Digital transformation has become very popular in recent years, organizations have mostly focused on improving only the area of information technology. According to Stark (2020) it is not only a technological change, but also a change in the organization, culture and business, "digital transformation is a complex and demanding process that requires the commitment of all the company's resources: human, technological, physical, organizational and financial.” (Kutnjak et al., 2019, p. 1293); it is about reworking strategies, products and processes 
taking advantage of digital technologies, seeking to give added value to the customer. According Katz (2018) affirms that digital transformation has generated a positive impact on production processes; Due to the fact that it allows the automation of processes and the decentralization of functions, optimizing the activities carried out by human capital, which leads to improving the use of material and financial resources. Rogers (2016) mentions that, there are five domains that describe the digital transformation landscape: (1) Customers, (2) competition, (3) data, (4) innovation and (5) value; which allows organizations to develop a different approach to innovation, because by using agility methodologies and design thinking, it is possible to maximize organizational learning and minimize costs. Almost all industries have been immersed in the digitization of their processes, the financial sector has not been the exception. Butler (2020) shows that, since banks and insurance companies are heavily regulated, they invest more than others in information technology, seeking to improve their operational processes, through the creation of new products with added value, pointing to new models of business with the purpose of improving the profitability of the company, in addition to building and maintaining a close relationship with the client.

According to Scardovi (2017), insurance companies face a crucial digital transformation challenge, as technological innovations are posing an unprecedented number of competitive threats and require accelerating the digitization of their business and operational processes. Traditional insurance companies depend to a great extent on sales channels, agents and physical intermediaries, which still show limited knowledge of digital tools; They still maintain a high level of manual processes, which leads to a risk related to reprocessing and complaints from customers, which in most traditional companies still retain old computer systems and collaborators have a deep-rooted cultural resistance. While insurance companies with digital knowledge have begun to innovate in their processes, creating a complete customer experience in all their channels, working with a comprehensive vision in their business model, focused on satisfying the customer's need, while continuing to side the digital and organizational culture of its stakeholders. Burcu and Sertaç (2018) mention that insurance companies managed to create new strategic experiences for customers, thanks to the analysis of data obtained in digital sales channels, as it improves the segmentation and identification of target customers; and the proper handling of Big Data has optimized risk management. According to the School of Senior Management and Administration (EADA), in its Second Report "Executive Digital Level in Peru 2019", it mentions that companies began to bet on creating areas of innovation and research, seeking to find new niches in the market, adapting to the needs of consumers who are increasingly demanding. Insurance companies took a long time to adapt to digitization (Albrecher et al., 2019). Therefore, the digital transformation in this sector arrived in Peru between 2016 and 2017 (UTEC, 2019), where few companies bet on the creation of value and incorporation of new technologies. Currently, the landscape has changed positively, more and more organizations are creating innovation laboratories, adopting design thinking in their processes, however, the great challenge is to adapt their organizational culture to the digital transformation that they have been developing, since they must operate in a macroeconomic context in which young companies pursuing technology-driven business models are expanding at a rapid pace (Braun \& Schreiber, 2017).

For Eling and Lehman (2018), digitization unites the analog with the digital and aims to profoundly modify the financial and insurance ecosystem, generating an impact on all the activities that make up the value chain of insurance companies, starting from the product development to pricing, underwriting, sales and distribution, claims, asset and risk management. Braun \& Schreiber (2017), mention that faster the insurance business adapts and integrates to digital innovation, the more likely it is that traditional insurers will survive, since the market context is constantly changing, and the profile of customers has varied over time, they are now in constant search of digital experiences throughout the insurance purchase journey. Likewise, insurance companies always sought to be close to their stakeholders and satisfy their needs; However, the situation caused by Covid-19 has generated that all industries have to accelerate their digital transformation process (Kim, 2020); Social distancing has put insurers to the test, so they have chosen to carry out remote work, prioritizing the development of applications in which the client can make inquiries and procedures without the need to go to a physical office. This scenario has generated that new technologies have changed the way insurers and clients interact, for example: social networks, applications, chatbots, video calls, among others (Eling \& Lehman, 2018). In this line of analysis, this research aims to measure the impact of digital transformation on the individual job performance of insurance companies in Peru.

\section{Literary review}

\subsection{Digital transformation}

According to Kutnjak et al. (2019, p. 1293), the digital transformation "is a complex and demanding process that requires the commitment of the entire company to use resources: human, technological, physical, organizational and financial, so digitalization implements digital tools throughout the organization, especially focus especially on people and business processes, based on the change of the business model". Along these lines Boateng, et al. (2020, pp. 26-44), affirm that, innovation, technology, creativity and digitization are the tools that are put at the service of customers, to make a transformative future a reality, for this they differ: "three key areas where executives of the company is being digitally transformed: customer experience, operational processes and business models, which change and form the foundations of the digital transformation process ". The technological leap in this era is exponential, therefore, digital transformation is not only a technological change, but also an organizational, cultural and management change that consists of reworking strategies, products and processes taking advantage of digital technologies, it is also the deep transformation of business models and competencies, organizational models, business processes and practices; all this, to satisfy the customers you want, from anywhere, at any time by managing information and improving the customer experience through digital technology (Stark, 2020). 
It is necessary to consider that the digital transformation generates a digital culture, with a new mentality to access knowledge because it is "the set of behaviors and habits developed and applied by managers and employees of an organization to take full advantage of the potential of new technologies, through better use and better dissemination throughout the organization in order to transform the business model or organizational models to create value for customers, employees and shareholders. " (Ochoa, 2016, p. 76). These behaviors and habits will allow to exploit benefits of technology that can improve the processes and results of the organization.

\subsection{Dimensions of Digital Transformation}

According to Kutnjak et al. (2019) "organizations focus especially on people (collaborator capacity) and business processes, driven by digital technology, which directly affects the change of their business model.” (p.1293).

\subsubsection{Dimension 1: Customer service experience}

The customer experience is the result of the reaction of a customer to certain stimuli of the company before, during and after the purchase of a product or service, likewise, the customer experience is the process of strategic management of all experiences of clients with a company (Bruhn \& Hadwich, 2012). For a client's experience to be optimal, Abolhassan (2017) affirms that "companies must change their strategic approach to the integral, as well as the individualized optimization of the customer experience customer in all digital media and traditional touch points, design plays an important role in terms of graphic presentation and user experience design, it is important to infer that simplicity, intuition and reactivity are key characteristics that companies must take mainly considered in the digital transformation of its user interface (front-end) and integration with the back office is not neglected; this It is because the processes of the support program (back-end) in logistics, accounting, warehousing or product development, can have the same impact on the customer experience, as well as on the customeroriented areas."(p. 13).

\subsubsection{Dimension 2: Collaborator capabilities}

According to Chiavenato Chiaventato $(2014$, p. 2), it is "the competences (qualities of someone who is capable of analyzing a situation, proposing solutions and solving issues and problems) that constitute the greatest personal assets, to be successful, the administrator must develop three durable competencies: knowledge, perspective and attitude". Likewise, Angulo (2017, the competences involve knowledge (conceptual), know-how (procedures) and knowing how to be (attitudinal) to define employee actions in the workplace, through the design and implementation of permanent training programs for the promotion of human talent, development of integration skills between people and teams, above technological investment, which become facilitators of knowledge management. Therefore, it has to do with a set of characteristics of workers such as their experience, knowledge, aspects related to their emotional state, attitudes, motivations, etc.; which must be aligned to the organization, that is, to technical, productive, customer service conditions, among others. It also plays a preponderant role culture at work, such as discipline, order, achievement of goals, etc. Overall, it can be said that work productivity or depends on a set of elements that promote good work performance in increasingly changing and demanding environments; along this line, according to Mohamad et al. (2016), it is necessary to develop competencies so that people face changes and work challenges, generating innovative ideas for solutions to different problems in their work practice.

\subsubsection{Dimension 3: Process}

There are several guidelines that must be followed when a company wants to bet on the change. According Stark (2020, p. 29) A business process is an organized set of activities, with clearly defined inputs and outputs, that creates business value; the business processes of an organization are generally divided into three main groups, these are: management processes, which includes quality regarding products and services according to an adequate planning of the processes; support processes, which creates value for internal customers, for people within the organization, and operational processes that create value for external customers (p. 29). In this regard, Galvis and González (2014) mention that business process management is a way to improve the visibility of the business and to equip organizations with skills and tools that allow them to respond quickly to changes and optimize benefits such as: (1) better understanding and visibility of processes, (2) improvement in handling exceptions and errors, (3) saving time and reducing costs due to increased efficiency of operations, (4) improvement in employee performance, and (5) possibility of improving processes based on evidence obtained by monitoring their execution.

\subsubsection{Dimension 4: Business model}

Vukanovic Z. (2016, p. 78), defines that "A business model has three components: content (What is consumed?), Customer experience (How is it packaged?) And platform (How is it delivered?) "These components work together to create a compelling value proposition for the customer." According to Abolhassan (2017), considering the stages of digital transformation, a business model encompasses: new sales, models, as well as new products and new business models. businesses that often lead to new digital ecosystems in the medium and long term, adding that companies will not be able to withstand the increasing competitive pressure on their own. 


\subsection{Individual job performance}

According to Chiavenato (2019), performance is "the set of characteristics or capabilities of behaviors or performance of a person, team or organization." (p. 206). While work methodologies have changed dramatically in recent years, employee performance management methods have changed at a much slower rate (Veingerl et al., 2020). The concept of performance entails different perspectives of analysis, in this line, Bauer et al. 2017) state that digital transformation has generated profound changes in all work dimensions, so four dimensions are essential to increase work performance: adaptation of workspaces (adaptive), integration of work processes (Intuitive), processes in real time (connected), and increase in digital systems (Assistance).

According to Ramos-Villagrasa (2019), the measurement of job performance can be carried out from different perspectives, and therefore its operationalization obeys different methodologies, in this sense, for the present study the contribution of Koopmans (2015) was considered, who identifies three core dimensions of job performance: (1) task performance, (2) contextual performance, and (3) counterproductive behavior (Fig. 1).

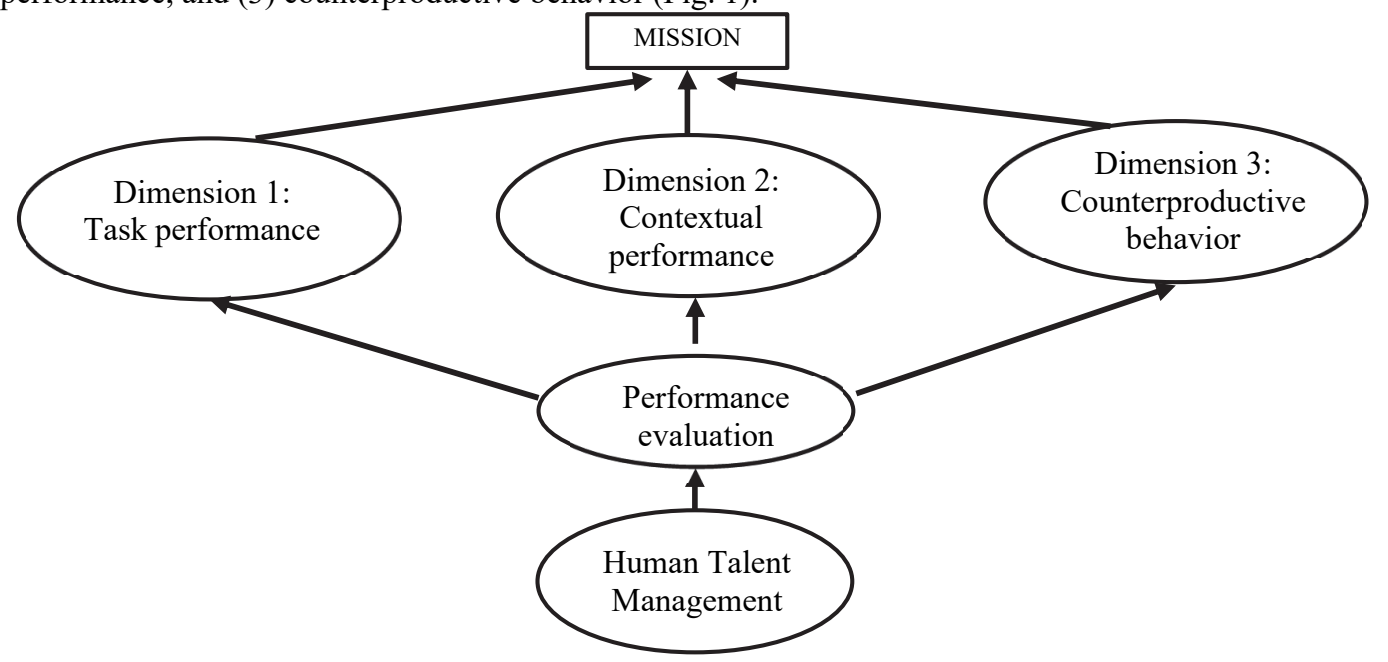

Fig. 1. Performance evaluation as a system.

Note. Prepared by the authors based on Koopmans (2015).

\subsubsection{Dimension 1: Task performance}

They are behaviors that contribute to the production of a good or the provision of a service (Rotundo \& Sackett, 2002). This dimension is the one that has traditionally received the most attention when evaluating worker performance, and according to Koopmans et al. (2016) represent the competencies that individuals demonstrate in their workplace.

\subsubsection{Dimension 2: Contextual Performance}

This dimension is known as organizational citizenship behavior, in that sense, it can be defined as behavior that contributes to the objectives of the organization by contributing to its social and psychological environment (Rotundo \& Sackett, 2002). The contextual dimension refers to all those behaviors that support the organization's environment, as well as the social and psychological aspects that workers show when developing their functions (Koopmans et al. 2016).

\subsubsection{Dimension 3: Counterproductive behavior}

It is voluntary behavior that harms the well-being of the organization (Rotundo \& Sackett, 2002). Along these lines, Bragg \& Bowling (2018), found a strong relationship between four personality traits (trait aggression, trait industriousness, trait deception, and trait self-control) and counterproductive work behavior (CWB for its acronym in English).

\section{Research Model and Hypotheses}

For the independent variable Digital Transformation, the following conceptual constructs and their respective items were considered:

a) Customer service experience (CSE): Digital customer service technologies provide a personalized experience (CSE1), digital channels offer a quick response in customer service (CSE2), customer satisfaction is measured in a permanent (CSE3) and digital processes protect customer data privacy (CSE4)

b) Collaborator capacity (CC): The training provided by the company on digital tools is adequate (CC1), I adequately adapt to the digitization process required by the company $(\mathrm{CC} 2)$ and I feel committed to the work that I develop in the process digitization of the company (CC3). 
c) Processes $(\mathrm{P})$ : The digitization of senior management processes contributes to the smooth running of the entire organization (P1), the digitization of processes of their team supervisors contributes to the achievement of their objectives (P2) and digitization of processes in his office has improved the efficiency in customer service (P3).

d) Business Model (BM): The company's value proposition consolidates customer loyalty (BM1), the company's digital business model contributes to the quality of customer service (BM2) and the digital platform covers the expectations of security and customer trust (BM3).

For the dependent variable Individual Labor Performance, the following conceptual constructs and their respective items were considered:

a) Task performance (TP): I plan my work to achieve the objectives established by the company (TP1), I establish priorities for the activities to be developed (TP2) and I meet my work goal in the expected time (TP3).

b) Contextual performance (CP): I take on challenging tasks when I complete my previous tasks (CP1), update my knowledge related to the work I perform (CP2), frequently develop my work skills (CP3), continually present creative solutions to new problems (CP4) and actively participate in meetings and / or consultations (CP5).

c) Counterproductive behavior (CB): I complain about the negative aspects of my job (CB1), problems at work, they often demotivate me (CB2), I focus on the negative aspects of situations of organizational change (CB3) and I talk to people outside the organization about the negative aspects of my work (CB4).

From which the following conceptual model and hypothesis are established.

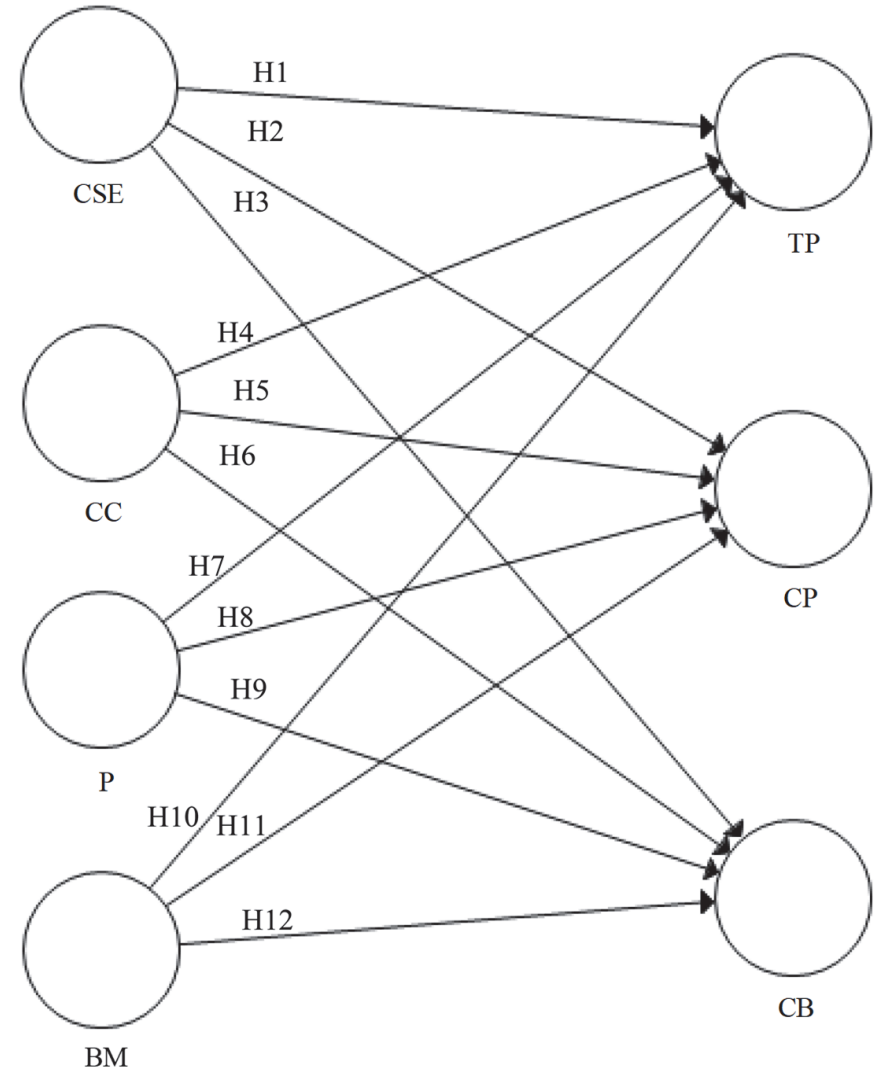

Fig. 2. Conceptual model and hypotheses

H1: The customer service experience (CSE) based on digital transformation generates a positive impact on task performance (TP).

$\mathrm{H} 2$ : The customer service experience (CSE) based on digital transformation generates a positive impact on contextual performance $(\mathrm{CP})$.

H3: The customer service experience (CSE) based on digital transformation generates a positive impact on counterproductive behavior $(\mathrm{CB})$.

H4: The capacity of the collaborator $(\mathrm{CC})$ based on digital transformation, generates a positive impact on task performance (TP).

H5: The capacity of the collaborator (CC) based on digital transformation, generates a positive impact on contextual performance $(\mathrm{CP})$. 
H6: The capacity of the collaborator (CC) based on digital transformation, generates a positive impact on counterproductive behavior (CB).

H7: Processes $(\mathrm{P})$ based on digital transformation generate a positive impact on task performance (TP).

H8: Processes (P) based on digital transformation generate positive impact on contextual performance (CP).

H9: Processes $(\mathrm{P})$ based on digital transformation generate a positive impact on counterproductive behavior (CB).

H10: The business model (BM) based on digital transformation generates a positive impact on task performance (TP).

H11: The business model (BM) based on digital transformation generates a positive impact on contextual performance (CP).

H12: The business model (BM) based on digital transformation generates a positive impact on counterproductive behavior (CB).

\section{Method}

The present study applied the deductive inferential scientific method, for which the type and level of applied and explanatory research were used respectively, since it was intended to measure the causal link that exists between the study variables. Likewise, the research design used is the non-experimental cross-sectional design.

\subsection{Population and sample}

The population is made up of workers from companies in the Peruvian insurance sector, made up of men (39.5\%) and women $(60.5 \%)$, with an age range between 25 years and over, who were the object of study. A sample of 305 workers from insurance companies was obtained, which are distributed in the north, center and south of Peru, located in the regions of Arequipa, Cusco, Iquitos, Lima, Tacna and Trujillo.

\subsection{Data collection instruments}

Questionnaires were designed and applied to the collaborators of the different insurance companies in Peru. The structure of the instrument presents 13 items for the digital transformation variable (four from customer service experience, three from collaborator capabilities, three from processes and three from business models) and 12 items for the individual job performance variable (three from performance work, five of contextual performance and four of counterproductive behaviors). For the validation of the instrument, the Delphi methodology was followed, likewise, the reliability was determined through the Cronbach's Alpha coefficient.

\section{Results}

\subsection{Assessment of the Measurement Model}

Table 1 shows the measurement analysis of the model, based on the reliability and validity of the measurement scales. Regarding reliability, the internal consistency of the scales is evidenced through the Cronbach Alpha value (between 0.785 to 0.880 ) and the composite reliability (between 0.860 to 0.916 ). With respect to convergent validity, all factor loadings are above 0.700 (Cordova et al., 2020). Likewise, all the scales have percentages of average variance extracted (AVE) greater than $50 \%$. The discriminant validity of the construct was tested by the Fornell Larcker criteria, which verifies the independence of each of the scales, considering that the square root of the AVE is greater than the correlations with the rest of the scales. In all cases, the assumption was met.

Table 1

Results of the model measurement analysis

\begin{tabular}{cccccc}
\hline Variables & $\begin{array}{c}\text { Cronbach } \\
\text { alpha }\end{array}$ & $\begin{array}{c}\text { Composite reli- } \\
\text { ability }\end{array}$ & $\begin{array}{c}\text { Factor loads } \\
\text { (range) }\end{array}$ & $\begin{array}{c}\text { Average variance } \\
\text { extracted (AVE) }\end{array}$ & $\begin{array}{c}\text { Discriminant } \\
\text { Validity }\end{array}$ \\
\hline CSE & 0.785 & 0.860 & $0.753-0.808$ & 0.606 & 0.779 \\
CC & 0.834 & 0.900 & $0.840-0.906$ & 0.751 & 0.867 \\
P & 0.838 & 0.903 & $0.831-0.902$ & 0.756 & 0.869 \\
BM & 0.846 & 0.906 & $0.861-0.889$ & 0.764 & 0.874 \\
TP & 0.828 & 0.897 & $0.835-0.901$ & 0.744 & 0.863 \\
CP & 0.861 & 0.900 & $0.695-0.858$ & 0.644 & 0.803 \\
CB & 0.880 & 0.916 & $0.811-0.883$ & 0.732 & 0.856 \\
\hline
\end{tabular}

As shown in Fig. 3, in all cases an R2 greater than 0.100 was obtained, which is very significant, showing that the model significantly explains the variance of the conceptual constructs of the dependent variable. 


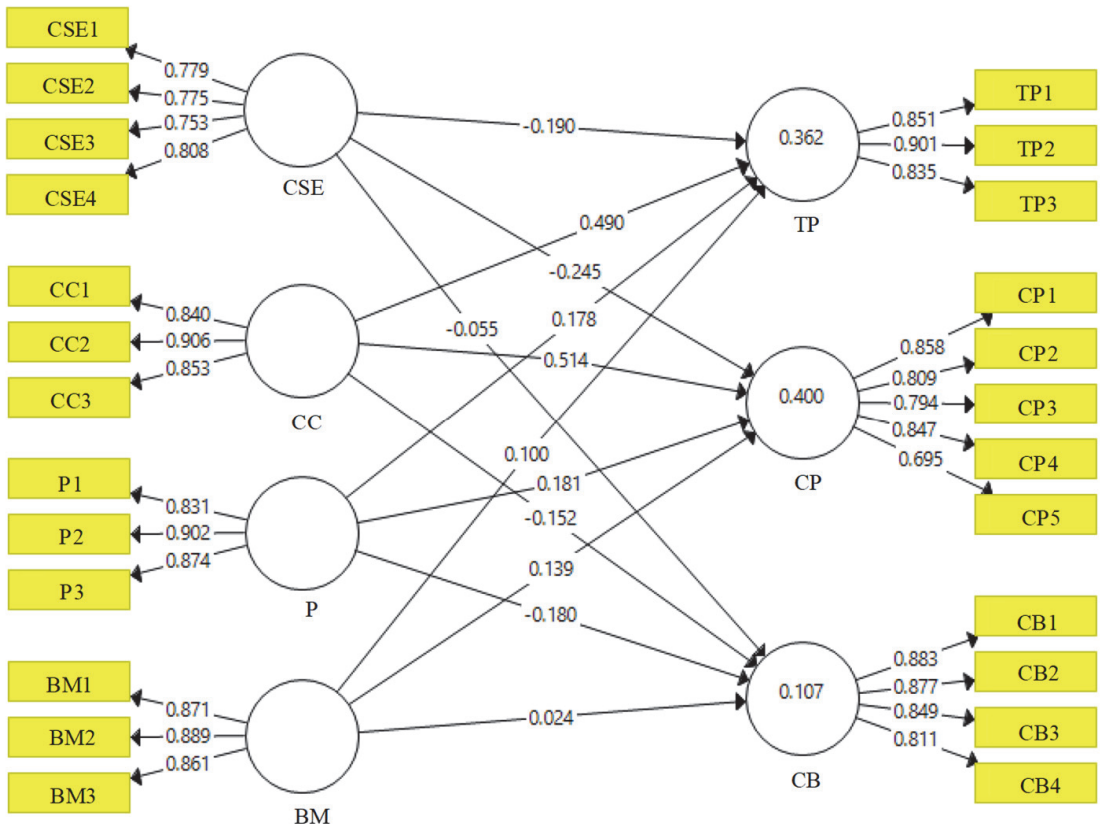

Fig. 3. Results for the hypothesized model with structural equations

\subsection{Assessment of the Structural Model}

After verifying the validity and reliability of the measurement model, the relationships of the constructs were tested. The hypotheses were tested by examining the path of the coefficients and their levels of significance. Bootstrapping was performed with 5500 subsamples to verify the statistical significance of each path of coefficients. Figure 3 shows the estimated trajectory of the PLS analysis.

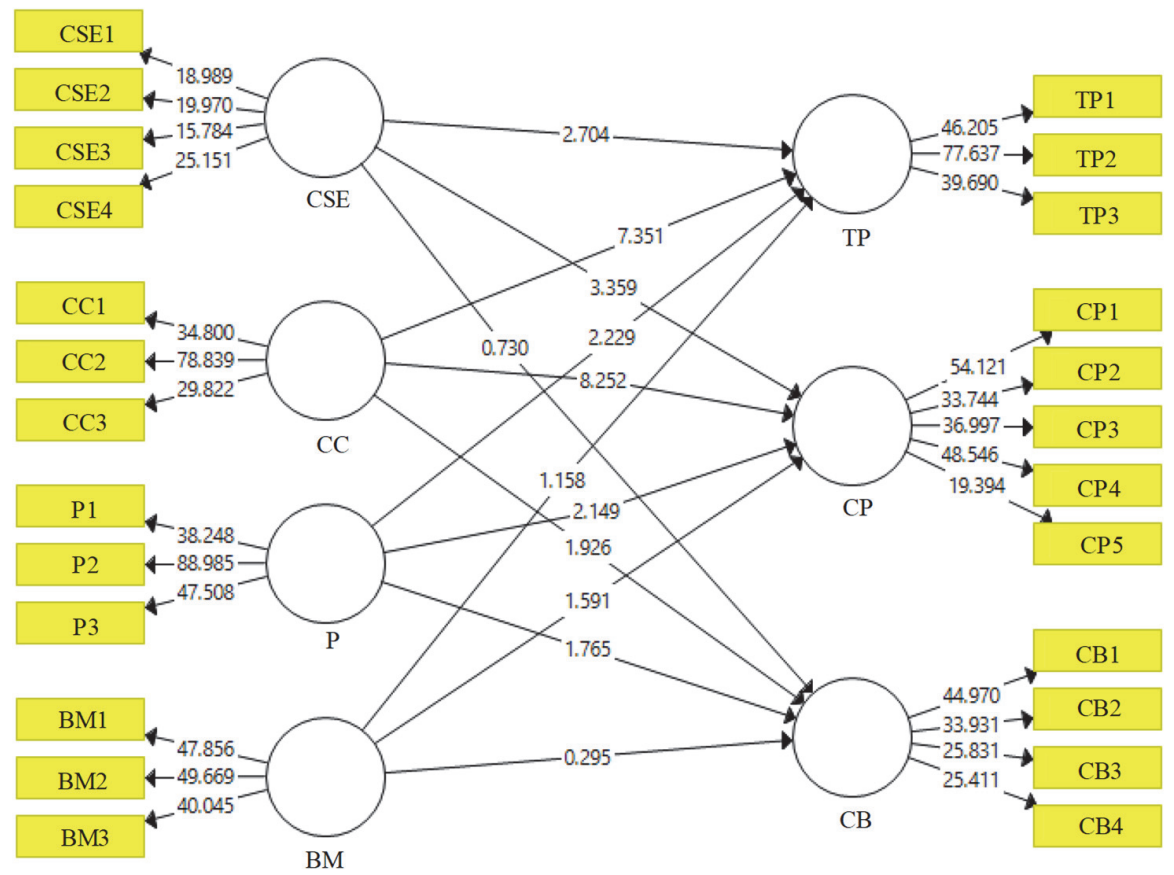

Fig. 4. Modeling digital transformation and individual job performance 
Considering that six specific relations have $\mathrm{p}<0.05$, the proposed hypotheses $\mathrm{H} 1, \mathrm{H} 2, \mathrm{H} 4, \mathrm{H} 5, \mathrm{H} 7$ and $\mathrm{H} 8$ are accepted as shown in Table 2:

Table 2

Results of the model structure analysis

\begin{tabular}{|c|c|c|c|c|c|}
\hline Hypotheses & Mean sample & Standard deviation & Beta & $\mathrm{p}$ value & Decision \\
\hline $\mathrm{CSE} \rightarrow \mathrm{TP}$ & -0.185 & 0.070 & 2.704 & 0.007 & Accept H1 \\
\hline $\mathrm{CSE} \rightarrow \mathrm{CP}$ & -0.242 & 0.073 & 3.359 & 0.001 & Accept H2 \\
\hline $\mathrm{CSE} \rightarrow \mathrm{CB}$ & -0.059 & 0.075 & 0.730 & 0.465 & Denies H3 \\
\hline $\mathrm{CC} \rightarrow \mathrm{TP}$ & 0.488 & 0.067 & 7.351 & 0.000 & Accept H4 \\
\hline $\mathrm{CC} \rightarrow \mathrm{CP}$ & 0.514 & 0.062 & 8.252 & 0.000 & Accept H5 \\
\hline $\mathrm{CC} \rightarrow \mathrm{CB}$ & -0.151 & 0.079 & 1.926 & 0.054 & Denies H6 \\
\hline $\mathrm{P} \rightarrow \mathrm{TP}$ & 0.180 & 0.080 & 2.229 & 0.026 & Accept H7 \\
\hline $\mathrm{P} \rightarrow \mathrm{CP}$ & 0.184 & 0.084 & 2.149 & 0.032 & Accept H8 \\
\hline $\mathrm{P} \rightarrow \mathrm{CB}$ & -0.180 & 0.102 & 1.765 & 0.078 & Denies H9 \\
\hline $\mathrm{BM} \rightarrow \mathrm{TP}$ & 0.098 & 0.086 & 1.158 & 0.247 & Denies H10 \\
\hline $\mathrm{BM} \rightarrow \mathrm{CP}$ & 0.136 & 0.087 & 1.591 & 0.112 & Denies H11 \\
\hline $\mathrm{BM} \rightarrow \mathrm{CB}$ & 0.025 & 0.083 & 0.295 & 0.768 & Denies H12 \\
\hline
\end{tabular}

\section{Discussion and conclusion}

Based on the results obtained, this document provides a description of the impact of digital transformation (from the dimensions: customer service experience, collaborator capabilities, processes and business model) on the individual job performance of companies in insurance in Peru.

Regarding the impact of the customer service experience, based on digital transformation, on individual job performance

In the study, it was found that the customer service experience, based on digital transformation, has a significant influence on the dimensions of task performance $(p<0.05)$ and contextual performance $(p<0.05)$, as well as a negative implication on the counterproductive behavior dimension $(\mathrm{p}>0.05)$. These results are in line with those of Ying-Yu et al. (2016), who mention that customer service services through the web portal: B2B functions and cloud computing services significantly influence the organizational performance of the Taiwanese textile industry. According to Itani et al. (2017), the proper use of social networks as digital tools, positively affects the performance of employees. Likewise, Stoeckli et al. (2019) affirm that the customer service experience, through chatbots, has been focused mainly on cost reduction and computer support for decisionmaking, in this way, its implementation provides added value by improving performance of internal workflows, in addition to taking advantage of the benefits of business systems such as alignment, control, interaction, operability and greater efficiency, in the context of information systems.

\section{Regarding the impact of the collaborator's capacity, based on the digital transformation in individual job performance}

The research results show that the collaborator's capacity, based on digital transformation, has a significant influence on the dimensions of task performance $(\mathrm{p}<0.05)$ and contextual performance $(\mathrm{p}<0.05)$, and a negative relation with the dimension of counterproductive behavior ( $\mathrm{p}>0.05)$.

Similar results were obtained by Mihova \& Ivanova (2020), who mention that Bulgarian organizations, immersed in the digitalization process, promote the adaptability of their collaborators to digital environments, which is related to the capacities of innovation, creativity and skills to team work; Therefore, the human resources area must redouble its efforts to constantly promote digital learning for its collaborators, so that they are highly effective and this provides optimal results by improving the performance of the organization. According to Winasis et al. (2020), 80\% of the employees of a private bank in Indonesia demonstrate commitment to the digital transformation that the financial sector is going through, where their employees have a high level of commitment, work with passion and have an emotional bond with the company, which leads to better job performance. Likewise, Maida et al. (2017), in an investigation carried out to an Indonesian insurance company, found that job satisfaction and leadership style are positively related to employee productivity, achieving a significant effect on company performance.

\section{Regarding the impact of the processes, based on digital transformation, on individual job performance}

The processes, based on digital transformation, have a significant influence on the dimensions task performance $(\mathrm{p}<0.05)$ and contextual performance $(\mathrm{p}<0.05)$, and a negative relation link with the counterproductive behavior dimension $(\mathrm{p}>0.05)$. Witherspoon (2015), affirms that adoption of information technologies in insurance companies, of the microinsurance category in Kenya, has been crucial for the performance of the insurance sector, generating a positive relationship with customer 
satisfaction, the performance of the personnel, product development and operational activities. In this line, Rosero (2019), argues that digital tools establish a positive influence of knowledge management with the dynamic capacity of organizational agility, which allows detecting and responding to changes in the environment, simplifying the ways of working and speeding up processes; reaffirming that organizational agility based on processes has a positive impact on organizational performance, production and operations, increasing labor productivity and the offer of products and services in companies.

\section{Regarding the impact of the business model, based on digital transformation, on individual job performance}

The business model, based on digital transformation, shows a negative relationship with the dimensions of task performance $(p>0.05)$, contextual performance ( $p>0.05)$ and counterproductive behavior ( $p>0.05)$. In this regard, Khansa et al. (2017), mention that, the use of social networks during the working day generates counterproductive behavior, which dissipates work resources and interferes with performance at work. Likewise, Farivar and Richardson (2020), affirm the advancement of information technologies has diversified the forms of work, one of them being remote work; however, working from home extends the number of working hours, which generates greater worker burnout. However, the findings of Shishi et al. (2016), indicated that customer service orientation, training, empowerment, affective organizational commitment, work stressors, and emotional exhaustion influenced the recovery of clients by staff. On the other hand, Pitoyo and Suharyanto (2020), mention that, the use of technological products in companies in the city of Bandung, Indonesia, generates great benefits by improving product quality, reducing time in manufacturing processes and services, which have a significant effect on the performance of employees.

While this document provides several contributions to the literature, there are limitations as there is little research on the impact of digital transformation and individual job performance, so further research is recommended to explore the role of the insurance industry digitization in intangible service companies, so that greater investment in research will contribute to the development of the sector.

\section{References}

Abolhassan, F. (2017). The Drivers of Digital Transformation. Germany: Springer International Publishing AG Switzerland.

Albrecher, H., Filipović, D., Bommier, A., Koch-Medina, P., Loisel, S., \& Schmeiser, H. (2019). Insurance: Models, digitalization and data science. European Actuarial Journal, 9, 349 - 360.

Angulo, R. (2017). Knowledge management and organizational learning: a comprehensive vision. Psychological Reports, $17(1), 59-62$.

Bauer, W., Schlund, S., \& Vocke, C. (2017). Working life within a hybrid world - how digital transformation and agile structures affect human functions and increase quality of work and business performance. Advances in human factors, business management and leadership. Advances in Intelligent Systems and Computing, 594, 3-10.

Boateng, R., Odoom, R., \& Kolog, E. (2020). Digital transformation process and the capability and capacity implications for small and medium enterprises. International Journal of E-Entrepreneurship and Innovation, 10(2), 26-44.

Bragg, C. B., \& Bowling, N. A. (2018). Not all forms of misbehavior are created equal: Differential personality facet-counterproductive work behavior relations. International Journal of Selection and Assessment, 26(3), 1-9.

Braun, A., \& Schreiber, F. (2017). The Current InsurTech Landscape: Business Models and Disruptive Potential. Switzerland, St. Gallen: Institute of Insurance Economics I.VW-HSG, University of St. Gallen.

Bruhn, M., \& Hadwich, K. (2012). Customer Experience: Forum Dienstleistungsmanagement. Germany: Springer Science + BusinessMedia.

Burcu, P., \& Sertaç, K. (2018). Digital Transformation in the Insurance Sector: The Case of Turkey. Journal of Industrial Policy and Technology Management, 1(2), $115-127$.

Butler, T. (2020). What's Next in the Digital Transformation of Financial Industry? IT Professional, 22 (1), 29-33.

Chiavenato, I. (2014). Administración de Recursos Humanos. Mexico: McGraw Hill.

Chiavenato, I. (2019). Administración de Recursos Humanos. Mexico: McGraw Hill.

Cordova, G., Surichaqui, S., Ricaldi, F., \& Vicente-Ramos, W. (2020). Impact of visual merchandising on the purchase decision of consumers from retail stores in central Peru. Management Science Letters, 10(11), 2447-2454.

Eling, M., \& Lehmann, M. (2018). The impact of digitalization on the insurance value chain and the insurability of risks. Geneva Papers on Risk and Insurance - Issues and Practice, 43(3), 359-396.

Escuela de Alta Dirección y Administración [EADA];. (2019). II Informe Nivel Digital Directivo en Perú 2019. Lima, Perú.

Farivar, F., \& Richardson, J. (2020). Workplace digitalisation and work-nonwork satisfaction: the role of spillover social media, Behaviour \& Information Technology. Behaviour \& Information Technology, 1-12.

Galvis-Lista, E. A., \& González-Zabala, M. (2014). Herramientas para la gestión de procesos de negocio y su relación con el ciclo de vida de los procesos de negocio: una revisión de literatura. Ciencia e Ingeniería Neogranadina, 24 (2), $37-55$.

Itani, O. S., Agnihotri, R., \& Dingus, R. (2017). The use of social media in B2b sales and its impact on competitive intelligence gathering and adaptive selling: Examining the role of learning orientation as a facilitator. Industrial Markrting Magement, 66, 64-79.

Katz, R. L. (2018). Capital humano para la transformación digital en América Latina. Desarrollo productivo, 1-40. 
Khansa, L., Kuem, J., Siponen, M., \& Kim, S. S. (2017). To Cyberloaf or Not to Cyberloaf: The Impact of the Announcement of Formal Organizational Controls. Journal of Management Information Systems, 34(1), 141-176.

Kim, R. Y. (2020). The impact of COVID-19 on consumers: Preparing for digital sales. IEEE Engineering Management Review, 8581(c), 1-1.

Koopmans, L. (2015). Individual Work Performance Questionnaire instruction manual. Amsterdam: NL: TNO Innovation for Life - VU University Medical Center.

Koopmans, L., Bernaards, C. M., Hildebrandt, V. H., Lerner, D., de Vet, H. C., \& van der Beek, A. J. (2016). Cross-cultural adaptation of the Individual Work Performance Questionnaire. Work, 53(3), 609-619.

Kutnjak, A., Pihiri, I., \& Furjan, M. T. (2019). Digital Transformation Case Studies Across Industries - Literature Review. In 2019 42nd International Convention on Information and Communication Technology, Electronics and Microelectronics (MIPRO), 1293-1298.

Maida, M. T., Riyanto, S., \& Ali, H. (2017). Effect of job satisfaction and leadership style towards employee productivity at PT Asuransi Umum Bumiputera Muda 1967. Saudi Journal of Business and Management Studies, 2, 157-168.

Mihova, T. B., \& Ivanova, I. M. (2020). Digitalization of HR activities in industrial enterprises. IOP Conference Series: Materials Science and Engineering, 878, 012069.

Mohamad, M., Ahmad, A., Sulaiman, n. L., Mohd, K., \& Chee, L. (2016). Vocational students' ability in invention process. Advanced Science Letters, 22(12), 4299-4302.

Ochoa, O. (2016). Digital culture: Building new organizarional behaviors and habits to maximize the potencial of technology. Economic studies bulletin, 217, 71-83.

Pitoyo, D., \& Suharyanto. (2020). The application of information technology, knowledge and skill and the impacts to employee performance. TSSA 2019 - 13th International conference on telecommunication systems, services, and applications, proceedings, 8985500, 82-88.

Ramos-Villagrasa, P., Barrada, J. R., \& Fernández-del-Río, E. K. (2019). Assessing job performance using brief self-report scales: The case of the individual work performance questionnaire. Journal of work and organizational psychology, 35 , 195- 205.

Rogers, D. L. (2016). The digital transformation playbook: Rethink your business for the digital age. New York: Columbia University Press.

Rosero, J. (2019). Transformación Digital y Desempeño Organizacional en Empresas del Sector de Energía Eléctrica. (Tesis de Maestría). Universidad Nacional de Colombia.

Rotundo, M., \& Sackett, P. R. (2002). The relative importance of task, citizenship, and counterproductive performance to global ratings of job performance: A policy-capturing approach. Journal of Applied Psychology, 87(1), 67-68.

Scardovi, C. (2017). Digital Transformation in digital services. London: Springer International Publishing.

Shishi, P., Muhammad, B., Niriender, P., \& Ariff, J. (2016). Factors Affecting Recovery of Service Performance and Customer Service Employees: A Study of the Malaysian Life Insurance Industry. International journal of productivity and performance management, 65(7), 898-924.

Stark, J. (2020). Digital Transformation of Industry. Geneva, Switzerland: Springer International Publishing.

Stoeckli, E., Dremel, C., Uebernickel, F., \& Brenner, W. (2019). How affordances of chatbots cross. Electronic Markets, 30, 369-403.

Universidad de Ingeniería y Tecnología [UTEC]. (2019). Transformación Digital en el Perú. Lima: Everis.

Veingerl Cic, Z., Vujica Herzog, N., \& Macek, A. (2020). Individual work performance management model. International Journal of Simulation Modelling (IJSIMM), 19(1), 112-122.

Vukanovic, Z. (2016). The paradigm shift: From static to evolutionary/dynamic/transformational/ networked/modular/dynamic business model concept. Switzerland: Springer International Publishing.

Winasis, S., Riyanto, S., \& Ariyanto, E. (2020). Digital transformation in the indonesian banking industry: Impact on employee engagement. International Journal of Innovation, Creativity and Change, 12 (4), 528-543.

Witherspoon, D. J. (2015). The influence of ICT adoption on performance of micro insurance business in Kenya. (Master Thesis). University of Nairobi.

Ying-Yu, K. C., Yi-Long, J., \& Bing-Li, W. (2016). Effect of digital transformation on organisational performance of SMEs: Evidence from the Taiwanese textile industry's web portal. Internet Research, 26 (1), 186-212.

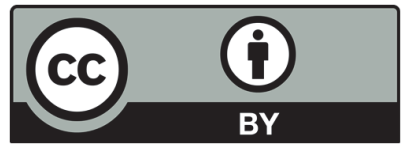

(C) 2020 by the authors; licensee Growing Science, Canada. This is an open access article distributed under the terms and conditions of the Creative Commons Attribution (CC-BY) license (http://creativecommons.org/licenses/by/4.0/). 